\title{
Máquinas e Números: traduções de Nicole Picard em Porto Alegre nos anos 1970
}

\author{
Elisabete Zardo Búrigo' \\ Nicolas Giovani da Rosa'
}

'Universidade Federal do Rio Grande do Sul (UFRGS), Porto Alegre/RS - Brasil

RESUMO - Máquinas e Números: traduções de Nicole Picard em Porto Alegre nos anos 1970. O artigo tem como foco leituras, traduções e citações de textos de Nicole Picard realizadas por professoras do Instituto de Educação General Flores da Cunha, em Porto Alegre, nos anos 1960 e 1970. As traduções são interpretadas como evidências de um encontro, por meio de textos, entre professoras que buscavam a renovação do ensino de matemática na escola primária, na França e no Brasil. Dentre os temas abordados, destaca-se o estudo de máquinas como representações de operadores, visando a compreensão das operações numéricas. No contexto do movimento da matemática moderna, o encontro foi favorecido pela valorização partilhada dos métodos ativos, da psicologia piagetiana e da sala de aula como objeto e âmbito de investigação sobre aprendizagem.

Palavras-chave: História da Educação. Ensino de Matemática. Ensino Primário. Formação de Professores. Matemática Moderna.

ABSTRACT - Machines and Numbers: translations of Nicole Picard's texts in Porto Alegre during the 1970s. The article focuses on readings, translations, and quotations of Nicole Picard's texts by teachers at the Instituto de Educação General Flores da Cunha, in Porto Alegre, in the 1960s and 1970s. The translations are interpreted as evidence of an encounter, through texts, between teachers who sought to renew the teaching of mathematics in elementary school, in France, and in Brazil. Among the themes addressed, the study of machines as representations of operators, aiming at the understanding of numerical operations, stands out. In the context of the modern mathematics movement, the meeting was favored by the shared valorization of active methods, Piagetian psychology, and the classroom as an object and scope of research on learning.

Keywords: History of Education. Mathematics Teaching. Primary Education. Teacher Education. Modern Mathematics.

Educação \& Realidade, Porto Alegre, v. 46, n. 2, e112151, 2021. 
Nos anos 1960 e 1970, o Instituto de Educação General Flores da Cunha, instituição formadora de professores, em Porto Alegre, foi um polo de discussão e propagação de ideias de modernização do ensino de matemática nos anos iniciais da escolaridade. Professoras do Instituto leram, estudaram, experimentaram e difundiram propostas de inovação curricular, por meio de cursos, palestras, artigos publicados em revistas pedagógicas. Na elaboração dessas propostas, foram tomados como referência autores de outras partes do país e do mundo, engajados na grande onda de reformas que ficou conhecida como "matemática moderna”. Em sintonia com as reformas no ensino secundário, esses autores advogavam mudanças no ensino de noções elementares, como a de número e operação numérica: seu estudo deveria estar ancorado na compreensão das ideias de conjunto e de estruturas matemáticas básicas (Bonfada; 2017; Búrigo, 1989; Silva, 2019).

Artigos, livros e materiais didáticos de Nicole Picard, pesquisadora do Institut Pédagogique Nacional (IPN) e coordenadora de uma experimentação desenvolvida na França, circularam no Instituto de Educação (IE) e, mais precisamente, no seu Laboratório de Matemática, um centro agregador de professoras interessadas na renovação do ensino. Traduções de extratos desses textos, encontrados no acervo do Laboratório, são evidências de uma mobilização para conhecer e divulgar as propostas da autora francesa. Esse achado é interessante, considerando-se que as menções a Nicole Picard, em estudos anteriores sobre a matemática moderna no Brasil, são escassas. Não se trata de uma autora que circulou pelo Brasil, articulando intercâmbios, como fizeram Georges Papy, Lucienne Félix ou Zoltan Dienes (Oliveira; Leme da Silva; Valente, 2011; D’Ambrosio, 2017). Nem se trata de uma autora cujo nome circulou amplamente pelo país, via livros didáticos, artigos em revistas ou na mídia.

Como, então, os escritos de Nicole Picard chegaram ao IE? Do que tratam as traduções de seus textos? Como as professoras do IE se mobilizaram para estudar e difundir seus escritos? Essas perguntas orientam a investigação e a discussão que sustentam a narrativa aqui apresentada.

Na perspectiva da história conectada, procuramos compreender a circulação e tradução dos textos de Nicole Picard não como desdobramento dos desenvolvimentos em curso no IE, nos anos 1960, nem como consequência da difusão de seus livros e materiais, que visavam o público francês, mas como uma articulação entre processos de modernização em curso nos dois países e, em especial, como conexão entre professoras engajadas nesses processos, na França e no Brasil. Destacamos o protagonismo de mulheres professoras, quando os autores do movimento modernizador mais conhecidos e citados, no âmbito internacional, eram homens.

Bertrand (2007, p. 70) descreve a história conectada como "história das conexões reais, isto é, das 'situações de contato' entre grupos de atores pertencendo a sociedades geograficamente distantes”. Compreender essas "situações de contato" envolve considerar os pontos de vista 
e as lógicas desses grupos de atores. Em acordo com essa perspectiva, apresentamos inicialmente o que consideramos como evidências de conexões entre Nicole Picard e as professoras do IE: as traduções encontradas no Laboratório de Matemática. A seguir, apresentamos brevemente as movimentações modernizadoras que precederam a recepção dos livros, no IE, e o contexto de produção dos livros de Picard, na França. Em um terceiro momento, tratamos propriamente da recepção, leitura e difusão dos textos em Porto Alegre, olhando com mais atenção para os temas e trechos que foram objeto de tradução, e apresentando algumas conjecturas sobre as escolhas que levaram à seleção desses extratos pelas professoras.

Com a narrativa desse encontro entre uma autora e suas tradutoras - que se deu sobretudo, mas não apenas, por meio dos livros e materiais didáticos - pretendemos iluminar mais um dos nós da trama pela qual se constituiu o movimento da matemática moderna, que teve como uma de suas características notáveis o intenso intercâmbio entre educadores que atuavam em diferentes etapas da escolaridade, em diferentes partes do mundo.

\section{Traduções de Nicole Picard no acervo do Laboratório de Matemática do IE}

O Laboratório de Matemática do Instituto de Educação foi constituído, em 1951, como um espaço para reunião de materiais didáticos produzidos pelas alunas da disciplina de Didática da Matemática do curso de Administração Escolar. Ao final da década, foi criado no seu âmbito um Círculo de Estudos, para discussão de textos e organização de cursos para professores (Instituto..., 1961).

As atividades foram intensificadas nos anos 1960 e se renovaram nas décadas de 1970 e 1980. O Laboratório foi desativado em algum momento, anos antes ou depois do ano 2000. A sala que abrigava o Laboratório passou a ser usada, também, como depósito de livros didáticos. Os documentos, livros e materiais didáticos, reunidos ao longo de 50 anos, ficaram guardados em caixas ou fichários de papelão. Em 2014, foram encontrados, cobertos de pó, por uma equipe de estudantes que participava do Programa Institucional de Bolsas de Iniciação à Docência (PIBID). O interesse pelos materiais didáticos motivou a equipe a reorganizar a sala, e o Laboratório foi revitalizado (Dalcin, 2016). Em 2016, quando o prédio do Instituto foi fechado para restauro, todos os materiais foram levados para uma sala do Instituto de Matemática e Estatística da Universidade Federal do Rio Grande do Sul ${ }^{1}$. Em 2017, teve início o projeto de constituição do acervo do Laboratório, com a higienização, inventário, acondicionamento e digitalização dos documentos² .

Durante o processo de inventário, foi possível perceber que os documentos, produzidos em diferentes épocas, haviam sido reagrupados e reordenados, nos anos 1980 e 1990, pois foram rubricados nesse período. Mas também é provável que tenham sido removidos ou rearranjados depois, sem um critério evidente: exemplares de um mesmo documento 
foram encontrados em caixas diferentes, alguns com folhas extraviadas. Em uma classificação inicial dos tipos de documentos, percebeu-se que havia muitas traduções; ao final do processo de higienização e inventário, foram listados 309 conjuntos de traduções manuscritas, datilografadas ou mimeografadas.

As atividades de traduções de textos sobre ensino de matemática, didática ou psicologia são também mencionadas nos relatórios da equipe do Laboratório, indicando que se tratavam de práticas regulares, planejadas e valorizadas. Muitos das traduções apresentam textos de autores vinculados ao movimento da matemática moderna, como Caleb Gattegno, Frédérique Papy e os já mencionados Lucienne Félix e Zoltán Dienes. Dezessete textos são traduções de extratos de obras de Nicole Picard ${ }^{3}$.

O Quadro 1 apresenta as traduções de Nicole Picard encontradas no acervo, identificando: o título atribuído a cada tradução, o número de tombo ou de registro do item no inventário, o título da obra a partir da qual foi extraído o trecho traduzido, a professora responsável pela tradução, o ano em que a tradução foi realizada, segundo os relatórios do Laboratório encontrados, a natureza do extrato, a modalidade do registro gráfico - manuscrito ou datilografado, eventualmente reprografado ${ }^{4}$, e o número de folhas ou páginas do item. Até o momento, não foi possível estabelecer o exemplar a partir do qual foi feita cada tradução.

\section{Quadro 1 - Traduções de textos de Nicole Picard encontradas no} Laboratório de Matemática do IE

\begin{tabular}{|c|c|c|c|c|c|c|c|}
\hline $\begin{array}{l}\text { Título da } \\
\text { tradução }\end{array}$ & Tombo & $\begin{array}{r}\text { Título do livro conten- } \\
\text { do o extrato original } \\
\end{array}$ & Tradutora & $\begin{array}{c}\text { Anoda } \\
\text { tradução }\end{array}$ & $\begin{array}{l}\text { Natureza } \\
\text { do extrato }\end{array}$ & Grafia & Folhas \\
\hline $\begin{array}{l}\text { Numera- } \\
\text { ção }\end{array}$ & 1973 & $\begin{array}{l}\text { Une expérience } \\
\text { d'enseignement de } \\
\text { la mathématique au } \\
\text { cours élémentaire. } \\
\text { In: Courrier de la } \\
\text { Recherche Pédago- } \\
\text { gique, n. } 27,1966 \text {. }\end{array}$ & $\begin{array}{l}\text { Agar Bau- } \\
\text { mgarten } \\
\text { Krebs. }\end{array}$ & 1967 & $\begin{array}{l}\text { Artigo em } \\
\text { revista } \\
\text { pedagó- } \\
\text { gica. }\end{array}$ & $\begin{array}{l}\text { Datilo- } \\
\text { grafado. }\end{array}$ & $2 \mathrm{f}$. \\
\hline $\begin{array}{c}\text { Uma } \\
\text { noção fa- } \\
\text { miliar às } \\
\text { crianças } \\
\text { do século } \\
\text { XX: a de } \\
\text { máquina }\end{array}$ & 2520 & $\begin{array}{l}\text { Recherche sur } \\
\text { l'initiation aux } \\
\text { mathématiques au } \\
\text { cycle élémentaire. } \\
\text { In: Courrier de la } \\
\text { Recherche Pédago- } \\
\text { gique, n. 31, 1967. }\end{array}$ & $\begin{array}{c}\text { Ely } \\
\text { Machado } \\
\text { Campos. }\end{array}$ & [1971] & $\begin{array}{l}\text { Artigo em } \\
\text { revista } \\
\text { pedagó- } \\
\text { gica. }\end{array}$ & $\begin{array}{l}\text { Datilo- } \\
\text { grafado. }\end{array}$ & $9 \mathrm{f}$. \\
\hline $\begin{array}{l}\text { Journal } \\
\text { CE2 } \\
\text { Prefácio }\end{array}$ & 2318 & $\begin{array}{l}\text { Journal de Mathé- } \\
\text { matique I. C. E. } 2 \text {. } \\
\text { Commentaires pour } \\
\text { le maître. }\end{array}$ & $\begin{array}{c}\text { Maria } \\
\text { Feijó Mon- } \\
\text { teiro. } \\
\text { Revisado } \\
\text { por Ely M. } \\
\text { Campos. }\end{array}$ & 1976 & $\begin{array}{l}\text { Orienta- } \\
\text { ção a pro- } \\
\text { fessores, } \\
\text { terceiro } \\
\text { ano. }\end{array}$ & $\begin{array}{l}\text { Manus- } \\
\text { crito, } \\
\text { a caneta, } \\
\text { em papel } \\
\text { de seda. }\end{array}$ & $8 \mathrm{f}$. \\
\hline
\end{tabular}


Búrigo; Rosa

\begin{tabular}{|c|c|c|c|c|c|c|c|}
\hline $\begin{array}{l}\text { Como } \\
\text { utilizar o } \\
\text { Jornal de } \\
\text { Matemá- } \\
\text { tica }\end{array}$ & 2317 & $\begin{array}{l}\text { Journal de Mathé- } \\
\text { matique I. C. E. } 2 . \\
\text { Commentaires pour } \\
\text { le maître. }\end{array}$ & $\begin{array}{c}\text { Maria } \\
\text { Feijó Mon- } \\
\text { teiro. } \\
\text { Revisado } \\
\text { por Ely M. } \\
\text { Campos. }\end{array}$ & 1976 & $\begin{array}{l}\text { Orienta- } \\
\text { ção a pro- } \\
\text { fessores, } \\
\text { terceiro } \\
\text { ano. }\end{array}$ & $\begin{array}{l}\text { Manus- } \\
\text { crito, } \\
\text { a caneta, } \\
\text { em papel } \\
\text { de seda. }\end{array}$ & $3 \mathrm{f}$. \\
\hline $\begin{array}{l}\text { Journal } \\
\text { CE2 Pro- } \\
\text { gressão } \\
\text { proposta }\end{array}$ & 2319 & $\begin{array}{l}\text { Journal de Mathé- } \\
\text { matique I. C. E. } 2 . \\
\text { Commentaires pour } \\
\text { le maître. }\end{array}$ & $\begin{array}{l}\text { Maria } \\
\text { Feijó Mon- } \\
\text { teiro. }\end{array}$ & 1976 & $\begin{array}{l}\text { Orienta- } \\
\text { ção a pro- } \\
\text { fessores, } \\
\text { terceiro } \\
\text { ano. } \\
\end{array}$ & $\begin{array}{l}\text { Manus- } \\
\text { crito, } \\
\text { a caneta, } \\
\text { em papel } \\
\text { de seda. }\end{array}$ & $5 \mathrm{f}$. \\
\hline $\begin{array}{l}\text { Organi- } \\
\text { zação do } \\
\text { espaço }\end{array}$ & $\begin{array}{l}1428, \\
2272\end{array}$ & $\begin{array}{l}\text { Journal de Mathé- } \\
\text { matique I. C. E. } 2 . \\
\text { Commentaires pour } \\
\text { le maître. }\end{array}$ & $\begin{array}{l}\text { Maria } \\
\text { Feijó Mon- } \\
\text { teiro. }\end{array}$ & 1976 & $\begin{array}{l}\text { Orienta- } \\
\text { ção a pro- } \\
\text { fessores, } \\
\text { terceiro } \\
\text { ano. } \\
\end{array}$ & $\begin{array}{c}\text { Datilo- } \\
\text { grafado. }\end{array}$ & $\begin{array}{l}5 \text { f. e } \\
\text { capa }\end{array}$ \\
\hline $\begin{array}{l}\text { Organi- } \\
\text { zação do } \\
\text { espaço }\end{array}$ & $\begin{array}{l}1421 \\
2445\end{array}$ & $\begin{array}{l}\text { Journal de Mathé- } \\
\text { matique I. Cours } \\
\text { élémentaire } 2 .\end{array}$ & $\begin{array}{l}\text { Maria } \\
\text { Feijó Mon- } \\
\text { teiro. }\end{array}$ & 1975 & $\begin{array}{l}\text { Ativida- } \\
\text { des para } \\
\text { alunos, } \\
\text { terceiro } \\
\text { ano. }\end{array}$ & $\begin{array}{l}\text { Datilo- } \\
\text { grafado e } \\
\text { repro- } \\
\text { grafado. }\end{array}$ & $9 \mathrm{f}$. \\
\hline $\begin{array}{l}\text { Organi- } \\
\text { zação do } \\
\text { espaço }\end{array}$ & 1905 & $\begin{array}{l}\text { Journal de Mathé- } \\
\text { matique I. C. E. } 2 . \\
\text { Commentaires pour } \\
\text { le maître. } \\
\text { Journal de Mathé- } \\
\text { matique I. Cours } \\
\text { élémentaire } 2 .\end{array}$ & $\begin{array}{l}\text { [Maria } \\
\text { Feijó Mon- } \\
\text { teiro] }\end{array}$ & $\begin{array}{c}1975 \mathrm{e} \\
1976\end{array}$ & $\begin{array}{c}\text { Orienta- } \\
\text { ção a pro- } \\
\text { fessores e } \\
\text { ativida- } \\
\text { des para } \\
\text { alunos, } \\
\text { terceiro } \\
\text { ano. }\end{array}$ & $\begin{array}{l}\text { Datilo- } \\
\text { grafado. }\end{array}$ & $22 \mathrm{f}$. \\
\hline $\begin{array}{l}\text { Organi- } \\
\text { zação do } \\
\text { espaço. } \\
\text { Quadri- } \\
\text { culados }\end{array}$ & 2442 & $\begin{array}{l}\text { Journal de Mathé- } \\
\text { matique Tome I à } \\
\text { partir du CE2. }\end{array}$ & $\begin{array}{l}\text { Maria } \\
\text { Feijó Mon- } \\
\text { teiro. }\end{array}$ & 1975 & $\begin{array}{l}\text { Ativida- } \\
\text { des para } \\
\text { alunos, } \\
\text { terceiro } \\
\text { ano. } \\
\end{array}$ & $\begin{array}{l}\text { Datilo- } \\
\text { grafado e } \\
\text { repro- } \\
\text { grafado. }\end{array}$ & $8 \mathrm{f}$. \\
\hline Esquemas & $\begin{array}{l}1429 \\
2312\end{array}$ & $\begin{array}{l}\text { Journal de Mathé- } \\
\text { matique I. C. E. } 2 . \\
\text { Commentaires pour } \\
\text { le maître. }\end{array}$ & $\begin{array}{l}\text { Maria } \\
\text { Feijó Mon- } \\
\text { teiro. } \\
\text { Revisado } \\
\text { por Ely M. } \\
\text { Campos. }\end{array}$ & 1976 & $\begin{array}{l}\text { Orienta- } \\
\text { ção a pro- } \\
\text { fessores, } \\
\text { terceiro } \\
\text { ano. }\end{array}$ & $\begin{array}{l}\text { Datilo- } \\
\text { grafado. }\end{array}$ & $5 \mathrm{f}$. \\
\hline Máquinas & 2569 & $\begin{array}{l}\text { Journal de Mathé- } \\
\text { matique I. C. E. } 2 . \\
\text { Commentaires pour } \\
\text { le maître. }\end{array}$ & $\begin{array}{c}\text { Ely } \\
\text { Machado } \\
\text { Campos. }\end{array}$ & 1971 & $\begin{array}{l}\text { Orienta- } \\
\text { ção a pro- } \\
\text { fessores, } \\
\text { terceiro } \\
\text { ano. }\end{array}$ & $\begin{array}{l}\text { Datilo- } \\
\text { grafado. }\end{array}$ & $9 \mathrm{f}$. \\
\hline Máquinas & 818 & $\begin{array}{l}\text { Journal de Mathé- } \\
\text { matique I. C. E. } 2 . \\
\text { Commentaires pour } \\
\text { le maître. }\end{array}$ & $\begin{array}{c}\text { Ely } \\
\text { Machado } \\
\text { Campos. }\end{array}$ & 1971 & $\begin{array}{c}\text { Orienta- } \\
\text { ção a pro- } \\
\text { fessores, } \\
\text { terceiro } \\
\text { ano. }\end{array}$ & $\begin{array}{l}\text { Datilo- } \\
\text { grafado e } \\
\text { repro- } \\
\text { grafado. }\end{array}$ & $9 \mathrm{f}$. \\
\hline
\end{tabular}

Educação \& Realidade, Porto Alegre, v. 46, n. 2, e112151, 2021. 


\begin{tabular}{|c|c|c|c|c|c|c|c|}
\hline $\begin{array}{l}\text { Numera- } \\
\text { ção }\end{array}$ & $\begin{array}{l}2321, \\
2320\end{array}$ & $\begin{array}{l}\text { Journal de Mathé- } \\
\text { matique I. C. E. } 2 . \\
\text { Commentaires pour } \\
\text { le maître. }\end{array}$ & $\begin{array}{l}\text { Maria } \\
\text { Feijó Mon- } \\
\text { teiro. }\end{array}$ & 1976 & $\begin{array}{l}\text { Orienta- } \\
\text { ção a pro- } \\
\text { fessores, } \\
\text { terceiro } \\
\text { ano. }\end{array}$ & $\begin{array}{l}\text { Manus- } \\
\text { crito, } \\
\text { a caneta, } \\
\text { em papel } \\
\text { de seda. }\end{array}$ & $\begin{array}{l}12 \mathrm{f} . \mathrm{e} \\
\text { capa }\end{array}$ \\
\hline $\begin{array}{l}\text { Organi- } \\
\text { zação do } \\
\text { espaço. } \\
\text { Polígo- } \\
\text { nos } \\
\end{array}$ & 2315 & $\begin{array}{l}\text { Journal de Ma- } \\
\text { thématique II. } \\
\text { Fascicule 1. Cours } \\
\text { Moyen } 1 .\end{array}$ & $\begin{array}{l}\text { Maria } \\
\text { Feijó Mon- } \\
\text { teiro. }\end{array}$ & 1976 & $\begin{array}{l}\text { Ativida- } \\
\text { des para } \\
\text { alunos, } \\
\text { quarto } \\
\text { ano. } \\
\end{array}$ & $\begin{array}{l}\text { Manus- } \\
\text { crito, } \\
\text { a caneta, } \\
\text { em papel } \\
\text { de seda. }\end{array}$ & $8 \mathrm{f}$. \\
\hline $\begin{array}{l}\text { Sistema } \\
\text { de nume- } \\
\text { ração }\end{array}$ & 1348 & $\begin{array}{l}\text { Activités mathé- } \\
\text { matiques I. Paris: } \\
\text { OCDL, [1969]. }\end{array}$ & $\begin{array}{c}\text { Léa Fagun- } \\
\text { des. }\end{array}$ & & $\begin{array}{l}\text { Orien- } \\
\text { tação a } \\
\text { professo- } \\
\text { res. } \\
\end{array}$ & $\begin{array}{l}\text { Datilo- } \\
\text { grafado e } \\
\text { mimeo- } \\
\text { grafado }\end{array}$ & $4 \mathrm{f}$. \\
\hline $\begin{array}{l}\text { Ativida- } \\
\text { des de } \\
\text { medição }\end{array}$ & 2322 & $\begin{array}{l}\text { Journal de Mathé- } \\
\text { matique I. C. E. } 2 . \\
\text { Commentaires pour } \\
\text { le maître. }\end{array}$ & $\begin{array}{c}\text { Maria } \\
\text { Feijó Mon- } \\
\text { teiro. } \\
\text { Revisado } \\
\text { por Ely M. } \\
\text { Campos. }\end{array}$ & 1976 & $\begin{array}{l}\text { Orienta- } \\
\text { ção a pro- } \\
\text { fessores, } \\
\text { terceiro } \\
\text { ano. }\end{array}$ & $\begin{array}{l}\text { Manus- } \\
\text { crito, } \\
\text { a caneta, } \\
\text { em papel } \\
\text { de seda. }\end{array}$ & $1 \mathrm{f}$. \\
\hline Ordem & 3068 & $\begin{array}{l}\text { À la conquête du } \\
\text { nombre. }\end{array}$ & & & $\begin{array}{l}\text { Ativida- } \\
\text { des para } \\
\text { alunos. }\end{array}$ & $\begin{array}{l}\text { Manus- } \\
\text { crito, } \\
\text { a caneta, } \\
\text { em papel } \\
\text { almaço. }\end{array}$ & $10 \mathrm{f}$. \\
\hline
\end{tabular}

Fonte: Elaborado pelos autores a partir da coleção digital Práticas e saberes matemáticos nas Escolas Normais do Rio Grande do Sul.

Pelo Quadro 1, vê-se que foram traduzidos trechos de dois artigos de Nicole Picard, publicados na revista pedagógica Le Courrier de la Recherche Pédagogique, uma publicação do Instituto Pedagógico Nacional (IPN) francês. Os extratos dizem respeito aos temas da numeração e das "máquinas", que correspondem à ideia matemática de operador, como comentaremos mais adiante.

As demais traduções correspondem a livros didáticos ${ }^{5}$ ou guias para o professor sobre o uso das fichas. A maioria são extratos do guia Commentaires pour le maître, de orientação a professores para uso do Journal de Mathématique I. C. E. 2, um conjunto de fichas de atividades para alunos do Cours élémentaire 2, ou C. E. 2 - o terceiro ano do ensino elementar na França, que reúne alunos com 8 a 9 anos de idade. No Journal, as fichas estão agrupadas por temas: Organização do Espaço, Esquemas, Máquinas e Numeração, nessa ordem. O estudo das operações numéricas é preparado pelo estudo dos temas precedentes e, em particular, pelo estudo das máquinas: "graças ao trabalho com as cadeias de máquinas numéricas, as crianças serão levadas a desenvolver a aptidão ao cálculo mental" (Picard, 1971, p. 37). As traduções dos extratos do guia Commentaires pour le maître, portanto, apresentam aos professores orientações para o trabalho com cada grupo de fichas.

Para compreender a recepção dos livros e a mobilização para a tradução dos textos, vamos tratar de eventos que os precederam, no La- 
boratório de Matemática do IE e na experimentação dirigida por Nicole Picard, na França.

\section{Movimentações para a modernização do ensino de matemática em Porto Alegre}

As movimentações que precederam a recepção dos livros de Nicole Picard, no Instituto de Educação, podem ser compreendidas a partir da conjugação de duas tendências: a construção de um ambiente de discussão sobre o ensino de matemática e, em particular, sobre a Didática da Matemática, desde o início dos anos 1950, no Laboratório de Matemática do IE; a emergência de um movimento de inovação curricular em âmbito internacional, mobilizando matemáticos, professores e agências governamentais, com fortes ressonâncias no Brasil.

Na constituição desse ambiente, tem sido destacado o protagonismo de Odila Barros Xavier, professora de Didática da Matemática que tomou a iniciativa da criação do Laboratório e foi sua principal impulsionadora por muitos anos (Dalcin; Bonfada; Rheinheimer, 2018). Em um texto retrospectivo, Odila Xavier menciona a leitura, desde os anos 1940, da obra de Piaget. A publicação da coletânea L'enseignement des mathématique, por Jean Piaget, Caleb Gattegno e matemáticos que participavam da Commission Internationale pour l'Étude et l'Amélioration de l'Enseignement des Mathématiques (CIEAEM), em 1955, logo recebeu a atenção de Odila e das professoras que frequentavam o Laboratório. Em particular, o capítulo Les structures mathématiques et les structures opératoires de l'intelligence, de Piaget (1955), conforme a professora Odila, abriu "novas perspectivas de interrogações e de buscas" (Xavier, 1963, p. 6). A partir do capítulo de Gattegno, La pédagogie des mathématiques, iniciou-se um estudo do material didático criado por George Cuisenaire.

Essas leituras teriam sido decisivas para a construção de um novo olhar para o ensino de matemática e motivaram um esforço de "atualização e aprimoramento, em matemática, dos professores primários" (Xavier, 1963, p. 8). Para essa atualização, foi decisiva a colaboração com Joana de Oliveira Bender, “[...] a primeira professora de matemática que valorizou, em Porto Alegre, nossos ingentes, penosos e quase dramáticos esforços de melhorar o ensino de matemática na escola primária” (Xavier, 1963, p. 9). Joana Bender, licenciada em Matemática e professora do Departamento de Matemática da Universidade Federal do Rio Grande do Sul (UFRGS), atuara por muitos anos no ensino primário como professora, diretora de grupo escolar e colaboradora do Centro de Pesquisas e Orientação Educacionais (CPOE). Desde 1953, a convite das professoras do IE, ministrou cursos sobre Teoria dos Conjuntos. O II Congresso Nacional de Ensino de Matemática, realizado em Porto Alegre, em 1957, também se constituiu em importante espaço de diálogo entre professores primários e secundários (Xavier, 1963; Búrigo, no prelo). 
Em 1961, o Laboratório de Matemática do IE já contava com uma pequena biblioteca que reunia livros de Matemática, como Conjuntos e funções de Leopoldo Nachbin e A Álgebra Moderna, de M. Queysanne e A. Delachet, e variadas obras do campo da Didática da Matemática, incluindo livros de autores ligados ao movimento modernizador, como Caleb Gattegno e Lucienne Félix, duas lideranças da CIEAEM. Nesse ano mesmo de 1961, o professor Antonio Ribeiro da UFRGS, a convite do Círculo de Estudos, ministrou mais um curso de Teoria dos Conjuntos para um público amplo de professoras, estudantes e técnicas do CPOE (Instituto..., 1961).

Essas movimentações no Instituto de Educação precederam a criação do Grupo de Estudos em Ensino de Matemática (GEEM), em São Paulo - considerada um marco para a deflagração do movimento da matemática moderna no Brasil. Uma grande onda renovadora seria impulsionada a partir de 1962, quando o GEEM apresentou uma nova proposta de programa para o ensino de matemática na escola secundária, no IV Congresso Brasileiro de Ensino de Matemática, em Belém do Pará. As proposições do GEEM foram recebidas pelas professoras do IE, nas palavras da própria Odila, "com emoção"; em particular, ela menciona o texto de Omar Catunda, preocupado em comunicar em uma linguagem simples as ideias de conjunto e estrutura, "conceitos esses básicos também para o trabalho da professora primária na direção da aprendizagem em matemática" (Xavier, 1963, p. 14).

Acompanhando as movimentações que se davam em âmbito nacional, com uma profusão de palestras, cursos de formação de professores, e divulgação de notícias na mídia, as professoras do IE, no início dos anos 1960, prosseguiram sua empreitada de estudos sobre a matemática moderna. Em 1965, um novo curso de Matemática foi ministrado pela professora Joana Bender, em 1965, com 144 participantes, sobretudo professoras formadoras e professoras da escola primária anexa ao IE (Instituto..., 1965).

Todas essas iniciativas indicam um grande interesse em acompanhar o movimento modernizador, de diversos modos: estudando novos materiais didáticos; conhecendo livros em circulação; estudando uma "matemática moderna", com novas noções e usos de linguagem, que não apenas era diferente da matemática então ministrada no Curso Normal do IE, mas também se distinguia da matemática preconizada pelos programas de ensino primário em vigor e, especialmente, da matemática aprendida pelas professoras ao longo de sua vida escolar e universitária.

Um novo personagem juntou-se ao grupo de professoras do IE em 1966. Esther Pillar Grossi fora contratada em 1965 como professora de matemática em uma turma de classe experimental do ginásio no Colégio Estadual Pio XII, em Porto Alegre. Em depoimento oral, ela relata que teve contato com as ideias da matemática moderna por meio de um curso de Lógica, ministrado em 1964 por Osvaldo Sangiorgi, presidente do GEEM, e pelos livros de Papy e Dienes, que já circulavam em Porto Alegre. E que fora incentivada a ensinar a matemática moderna por Lu- 
cienne Félix, durante sua visita a Porto Alegre em agosto de 1965. Em janeiro de 1966, Esther apresentou um relato de sua experiência no V Congresso Brasileiro de Ensino de Matemática, em São José dos Campos; então teve contato com professoras do IE, que a convidaram para trabalhar naquela instituição (Grossi, 1988; 2007a).

No mesmo ano de 1966, iniciou-se a oferta de um curso de especialização em Didática da Matemática Moderna para a Escola Primária, com duração de um ano e meio, destinado a professores primários e da pré-escola do próprio Instituto. As professoras de Didática da Matemática no IE, conforme requeria a legislação, eram diplomadas em Pedagogia. A Esther Grossi, licenciada em Matemática, foi confiada a disciplina de Fundamentação Matemática, com 93 encontros semanais (Instituto..., 1967a).

Os primeiros livros de Nicole Picard chegaram ao Laboratório em 1967, quando o curso avançava para o seu segundo ano: Des ensembles à la découverte du nombre; À la conquête du nombre, e Blocs logiques, destinados a alunos e professores da educação infantil e do primeiro ano do ensino elementar. De acordo com o Relatório de Atividades de 1967, foram adquiridos naquele ano um total de 56 livros para o Laboratório de Matemática, sendo 24 livros da autoria de Nicole Picard (Instituto..., 1967b).

Ainda em 1967, foram iniciadas em algumas escolas particulares de Porto Alegre classes experimentais no primeiro ano primário, orientadas pelo curso de especialização e inspiradas nos livros de Nicole Picard; em 1968, foi iniciada experiência na escola primária do próprio Instituto de Educação (GEEMPA, 1975; Instituto..., 1970).

\section{Livros didáticos elaborados a partir da experimentação em salas de aula}

Os livros de Nicole Picard encontrados no Laboratório de Matemática distinguem-se de outros materiais pelo seu formato e intenção. Os livros dirigidos aos alunos consistem em coleções de fichas, numeradas conforme a ordem aconselhada para o seu uso. Essas fichas trazem atividades a serem realizadas pelas crianças, colorindo objetos, completando esquemas gráficos, escrevendo números; os livros para professores apresentam a fundamentação para as atividades propostas, a lógica envolvida na sequência delineada e orientações pormenorizadas para a realização de cada atividade. O uso das fichas não é o típico de um livro, pois elas podem ser rearranjadas, ou visualizadas ao mesmo tempo, o que não se pode fazer com as páginas de um livro. A Figura 1 mostra um dos livros encontrados no acervo.

Cada livro é destinado prioritariamente a uma série do ensino elementar; mas a autora adverte sobre a importância de "seguir o ritmo próprio de cada criança e, em particular, de suprimir as reprovações que apenas em circunstâncias excepcionais são proveitosas”, de modo que algumas crianças poderiam não concluir uma sequência de estu- 
dos e atividades em determinada série, continuando "no ano seguinte, sem entretanto serem maus alunos" (Picard, 1971, p. 9).

Figura 1 - Imagens da coleção de fichas Journal de Mathématique I C. E. 2 et exercices

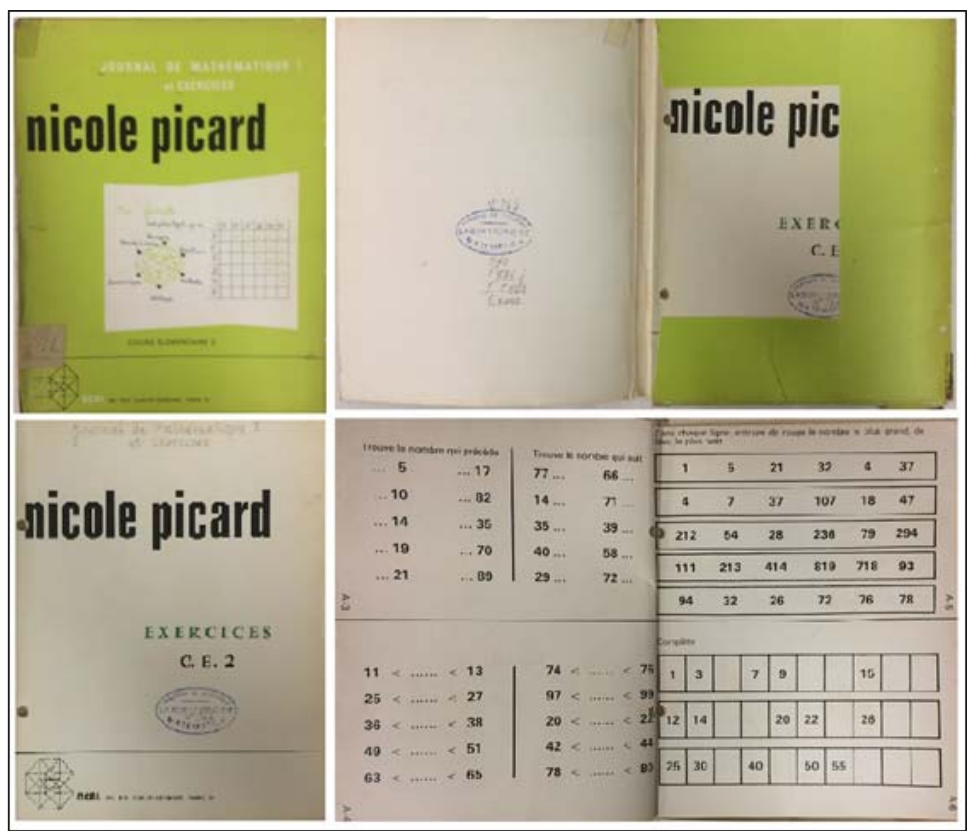

Fonte: Acervo do Laboratório de Matemática do Instituto de Educação General Flores da Cunha.

Para compreender o formato e a intenção dos livros, é importante considerar o contexto de sua produção: Nicole Picard, licenciada em Matemática, coordenou uma experimentação sistemática de renovação do ensino de matemática na escola primária, empreendida pelo Departamento de Pesquisa Pedagógica do IPN, a partir do ano letivo de 1964-1965, até 1970. Também participou da Comission d'étude pour l'enseignement des mathématiques (CEEM), instituída em 1966 pelo Ministério da Educação para planejar uma reforma do ensino (Picard, 1973).

As propostas de mudança no ensino primário, na França, eram fortemente inspiradas nos debates sobre a modernização do ensino de matemática, nas universidades e escolas secundárias. Desde os anos 1940, no pós-guerra, o grupo de matemáticos de pseudônimo Bourbaki propunha uma reorganização dos cursos universitários em torno das estruturas matemáticas, valorizando o estudo de objetos e propriedades mais gerais, assentado em uma axiomática rigorosa. Professores secundários e universitários, reunidos em diferentes fóruns, defendiam que esse enfoque fosse adotado, com adaptações, para o ensino secundário, como uma alternativa a um ensino fragmentado e baseado 
na reprodução de técnicas mal compreendidas. A abordagem estruturalista era articulada à defesa dos métodos ativos: as propriedades deveriam ser descobertas ou construídas pelos alunos. Ao final da década de 1950, já se propunha trazer o novo enfoque para o ensino elementar e a pré-escola: tratava-se de envolver os alunos, desde cedo, em atividades que promovessem o desenvolvimento do pensamento matemático (D’Enfert, 2011).

Professores secundários de matemática mobilizaram-se na direção da renovação do ensino elementar, com a intenção de formar e orientar experiências a serem desenvolvidas pelos professores primários. Em 1960, Lucienne Félix publicou o livro Mathématiques modernes: enseignement élémentaire, dirigido a professores da escola primária e do primeiro ciclo do secundário. A convite de Roger Gal, que coordenava o Departamento de Pesquisa Pedagógica do IPN francês, Lucienne Félix produziu, de 1961 a 1963, um boletim intitulado Education et mathématiques, dirigido a professores primários (Gal, 1966). Em 1965, Guy Brousseau, então professor do ensino elementar, publicou Les Mathématiques du cours préparatoire, um livro com atividades, dedicado às crianças do primeiro ano (6 anos de idade).

Nicole Picard menciona as produções de Lucienne Félix e Guy Brousseau em seus artigos. Mas para justificar uma experimentação mais ampla, como preparação de uma reforma, ela destaca projetos desenvolvidos em outros países, especialmente em diferentes partes dos Estados Unidos, sob a direção de equipes das universidades. Na perspectiva de Picard, todos corroboravam a ideia de que as crianças poderiam construir seu próprio "universo matemático" (Picard, 1966, p. 22) se tivessem a oportunidade de realizar atividades variadas, estabelecer relações e construir suas próprias representações. A principal referência para a experimentação, contudo, eram os escritos de Zoltan Paul Dienes, que iniciara um projeto em Leicester, Inglaterra, e fora professor visitante na Universidade de Adelaide, na Austrália, de 1961 a 1965. (Picard, 1966). Dienes orientou estágios no IPN em 1965 e, segundo Louis Legrand, sucessor de Roger Gal, Dienes teria sido um dos grandes impulsionadores da investigação coordenada por Picard (Legrand, 1967).

Inspirado nos estudos de Jean Piaget sobre o isomorfismo entre as estruturas matemáticas e as estruturas da inteligência, e sobre as diferentes etapas de desenvolvimento do pensamento lógico-matemático, Dienes defendia um processo de aprendizagem inteiramente sustentado na construção dos conceitos e das estruturas pelas crianças. Para tanto, propunha intensa atividade com materiais manipuláveis, precedendo a escrita, e a interação entre as crianças por meio de jogos e discussões.

A empreitada do IPN teve início com turmas de primeiro ano do ensino elementar (cours préparatoire, 6 a 7 anos de idade), em três escolas de Paris: a École Alsacienne, laica e privada, lugar de variadas inovações desde o século XIX, e duas escolas públicas - uma de meninos e outra de meninas. No ano seguinte, a experiência foi estendida 
a turmas de segundo ano (cours élémentaire 1) e a classes experimentais de primeiro e segundo ano em diferentes regiões da França. Assim prosseguiu, alcançando a cada ano mais uma série do ensino primário (Picard, 1966; 1967).

Para orientar o trabalho dos professores nas escolas, e foi construído um roteiro de temas a serem abordados, bastante diferente do programa em vigor, ainda que preservando seus tópicos principais. Assim, por exemplo, atividades de classificação, de estabelecimento e estudo de relações entre elementos de um conjunto ou entre conjuntos, e de operações com conjuntos deveriam preceder o estudo dos números. O estudo dos operadores deveria preceder o das operações numéricas, como veremos mais adiante primário (Picard, 1966; 1967).

Como coordenadora da grande experimentação, Nicole Picard desempenhava vários papéis, ao mesmo tempo. Animava reuniões quinzenais de discussão sobre a matemática moderna e a experimentação, com professores e pesquisadores, no IPN; elaborava roteiros, atividades e materiais a serem experimentados; coordenava, registrava e avaliava a experimentação em algumas escolas, notadamente, na École Alsacienne de Paris. Sobre as reuniões no IPN, ela relata que reuniam cerca de 15 pesquisadores no início, e foram se ampliando, agregando 120 no último ano (Picard, 1973).

Pode-se supor que as orientações gerais do processo eram tratadas nesse debate amplo. Entretanto, o detalhamento e, sobretudo, a validação da experimentação era construída no acompanhamento das salas de aula:

Para todos [professores] forneci durante o ano tipos de exercícios acompanhados, na medida do possível, de fichas pedagógicas com a finalidade de explicar aos professores os porquês das coisas. Também fui às salas de aula mas, para dizer a verdade (eu não sei a opinião dos professores sobre isso), eu não acredito que minha presença fosse indispensável aos professores, a não ser quando havia uma dificuldade particular que tentávamos resolver juntos, ali mesmo, na sala de aula. Em contrapartida, para mim, aquilo era extremamente precioso. A organização da experiência era tal que eu não dispunha de um 'laboratório' onde ensaiar, testar as ideias tanto matemáticas quanto pedagógicas que me pareciam válidas, de modo que eu reunia em um canto da sala grupos de 4 a 8 alunos que eu fazia trabalharem, cujas reações eu anotava tão cuidadosamente quanto possível, e com os quais eu testava exercícios antes de os mostrar à professora (Picard, 1966, p. 22).

A experiência era conduzida em modo artesanal, mas havia, desde o início, uma ambição de sua generalização a todas as escolas primárias francesas. Em 1966, Nicole Picard inicia a publicação de relato detalhado da experiência em curso, na revista Courrier de la Recherche Pédagogique. No mesmo ano, inicia a publicação de sua coleção, com o 
livro Des ensembles à la découverte du nombre, destinado aos professores da pré-escola e do primeiro ano do curso elementar, e À la conquête du nombre, um conjunto de fichas para uso dos alunos do primeiro ano. As ideias modernizadoras também foram divulgadas por filmes, transmitidos pela Radio Télévision Scolaire de 1964 a 1971.

De outubro de 1968 e durante todo o ano de 1969, Esther Pillar Grossi reside em Paris, sendo convidada a estagiar no IPN, sob a orientação de Nicole Picard, e frequentar curso de mestrado na Universidade de Paris, sob a orientação de Pierre Gréco, pesquisador da psicologia do desenvolvimento cognitivo e antigo colaborador de Piaget. Nesse período, acompanha as aulas na École Alsacienne, observando as atividades e discussões das crianças, fazendo anotações e participando das reuniões de planejamento e avaliação da experimentação em andamento (Grossi, 2007b).

De volta a Porto Alegre, em 1970, Esther Grossi desenvolve intensas atividades no Laboratório de Matemática do Instituto de Educação. Retoma o curso de Didática da Matemática Moderna na Escola Primária, ministrando 96 horas de aula; profere um ciclo de palestras, semanais, sobre Matemática Moderna no Jardim de Infância e na Escola Primária; coordena reuniões semanais de estudo; realiza orientação semanais às professoras envolvidas na Experiência de Renovação do Ensino da Matemática na Escola Primária do IE, iniciada em 1968 e coordenada pela professora Maria Celeste Koch (Instituto..., 1970).

Em 1968, ela já havia publicado, na Revista do ensino, periódico dirigido aos professores primários do Rio Grande do Sul, o artigo Introdução à topologia do plano, reproduzindo atividades constantes do tomo Topologie, do livro À la conquête du nombre. Em 1971, publica uma série de três artigos com o título Matemática chamada moderna no primeiro ano primário, apresentando relatos de experimentação em Porto Alegre e atividades inspiradas nos livros de Dienes e de Picard.

Aulas, palestras, reuniões de estudo, artigos na Revista do Ensino foram espaços de divulgação das ideias e dos materiais de Nicole Picard. Todavia, em 1971 já não encontramos referências a Esther Grossi nos relatórios do Laboratório de Matemática. Podemos presumir que nessa época Esther se afastou do Laboratório para se dedicar ao recémfundado Grupo de Estudos em Ensino de Matemática de Porto Alegre (GEEMPA), do qual era principal articuladora e presidente. Tendo sido a primeira e a mais conhecida divulgadora de Nicole Picard em Porto Alegre, Esther contudo não consta como responsável pelas traduções de seus textos encontradas no Laboratório do IE.

\section{Máquinas: estudo e prática das ideias de Nicole Picard}

Somente a presença dos livros de Nicole Picard no acervo do Laboratório de Matemática não nos revela muito sobre o interesse das professoras do Instituto de Educação em sua obra. Porém, as traduções realizadas nos indicam alguns de seus objetivos de estudos. Por outro lado, 
atividades de cursos, produções de professoras e alunas, exemplificam como e quando as ideias da autora francesa eram colocadas em prática.

Em seus livros, Picard escreve sobre suas experiências de pesquisa, articulando teoria e prática. Em artigo publicado no ano de 1967, relata experiência desenvolvida com turmas do cours élementaire 2 sobre o trabalho com as máquinas. $\mathrm{O}$ trecho do artigo foi traduzido por Ely Machado Campos, professora de Didática da Matemática, conforme mostra o Quadro 1. O relatório de 1971 indica que a tradução foi realizada naquele ano e que Máquinas era um dos assuntos mais procurados nas consultas de professores e estudantes que visitavam o Laboratório (Instituto..., 1971).

A proposta de estudo das máquinas é inspirada nos escritos de Dienes sobre operadores. Depois de explorar diferentes tipos de relações em diferentes conjuntos (por exemplo, a relação dada por ser irmão de ou ser mais velho que), o trabalho se concentra em relações funcionais (a cada elemento do conjunto de partida corresponde no máximo um elemento do conjunto de chegada, como na relação dada por ser filho $d e$, em um conjunto de homens). E então, dentre as relações funcionais, destacam-se "aquelas que transformam um estado inicial em um estado final; nós as designaremos sob o nome de operador" (Picard, 1967, p. 12, nossa tradução, grifos no original). Argumentando que a noção de que uma máquina transforma é uma noção familiar para as crianças do século XX, as atividades com máquinas são propostas como caminho para aquisição dos conceitos de operador e função. Sempre privilegiando as noções mais genéricas, a abordagem proposta por Picard é iniciar explorando máquinas não numéricas, por exemplo, máquinas que transformam objetos manipuláveis como os blocos lógicos (Picard, 1967). A Figura 2 mostra uma caixa de blocos lógicos produzidos pela editora Office central de librairie (OCDL), adquiridos pelo Laboratório de Matemática, com referência ao matemático e psicólogo Zoltan Dienes ${ }^{6}$.

Figura 2 - Conjunto de blocos lógicos

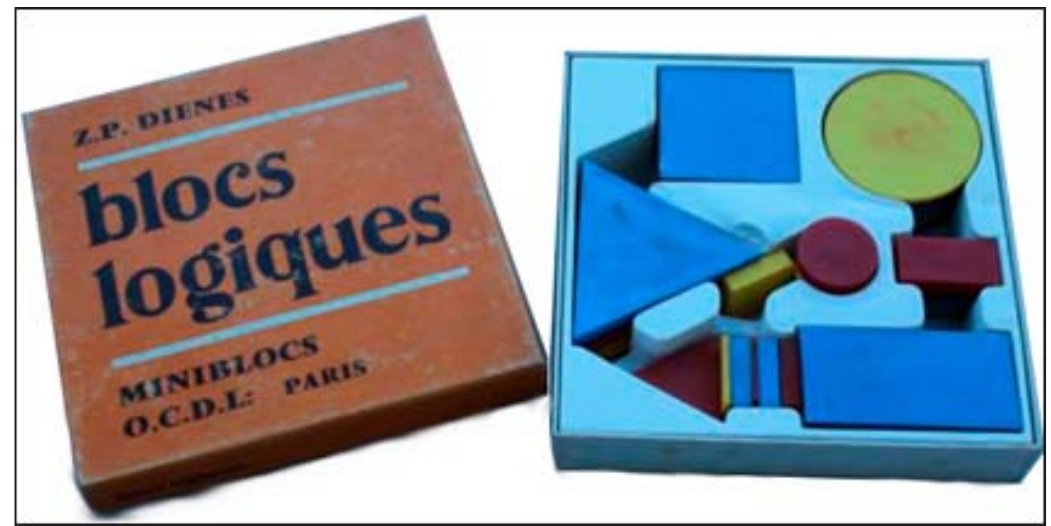

Fonte: Acervo do Laboratório de Matemática do Instituto de Educação General Flores da Cunha. 
O texto traduzido por Ely Campos traz registros do diário de campo de Nicole Picard, de uma situação em que ela interagiu diretamente com um grupo de crianças em sala de aula. Ela relata que crianças de uma turma da experimentação foram convidadas a simular máquinas que mudam a cor, máquinas que mudam a forma, máquinas que mudam cor e forma de objetos. Depois dramatizaram o funcionamento de uma fábrica, fazendo máquinas funcionar em cadeia; sendo cada máquina representada por uma criança. Uma criança então escolhia um objeto para ser transformado e outras eram encarregadas de descobrir o produto da transformação operada por cada máquina. A partir da dramatização, várias questões foram propostas às crianças: é possível substituir toda a fábrica por uma máquina apenas? A partir desse estudo da composição de transformações, foram investigadas várias propriedades: a existência de máquinas que não fazem nada (elemento neutro), a comutatividade e a associatividade da composição, e a existência da máquina que desfaz o que outra faz (elemento inverso).

Os operadores numéricos foram introduzidos a partir da observação das situações de entrada e de saída representadas na Figura 3, as quais as crianças identificaram com uma máquina que junta dois objetos, à qual Nicole faz corresponder a escrita +2 em uma lousa.

Figura 3 - Representação de Nicole Picard para uma máquina que junta dois objetos

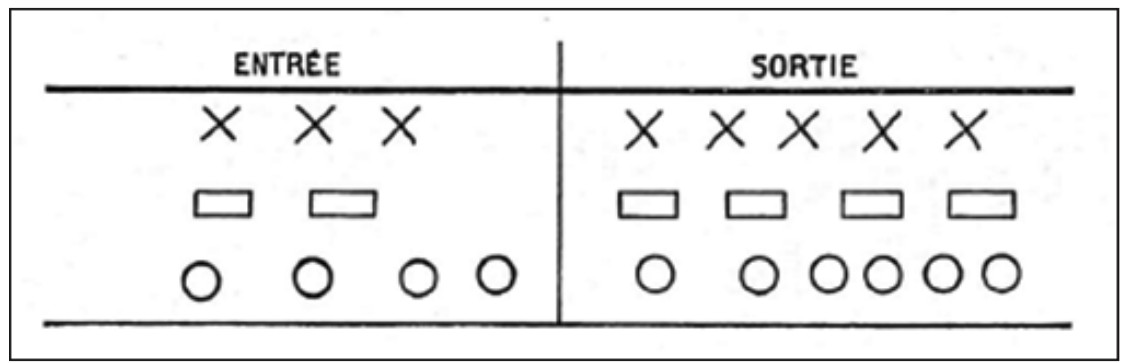

Fonte: Picard (1967, p. 18).

A seguir, foi construída uma fábrica: em pequenas lousas, usadas pelas crianças na época, foram escritos os operadores numéricos: $+2,+3,-2,+5,+1$ e assim por diante, representando as ações de juntar e retirar uma certa quantidade de objetos de uma coleção. Cada criança segurando uma lousa representava então uma máquina. Uma criança dizia um número para a primeira máquina, outra criança dizia o resultado, que alimentava a próxima máquina, e assim por diante. A Figura 4 ilustra a dramatização narrada por Picard (1967). A partir da discussão, foi discutido com as crianças qual máquina poderia substituir uma determinada sequência, se uma máquina poderia ser substituída por duas ou mais, e assim por diante. 
Figura 4 - Cadeia de máquinas que somam e subtraem

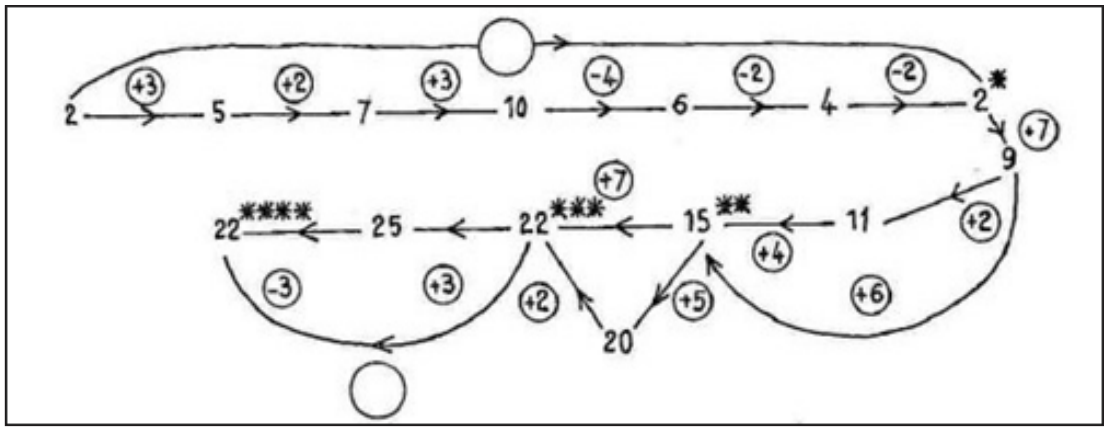

Fonte: Picard (1967, p. 19).

Todo o trabalho com máquinas deveria preparar o estudo das operações numéricas. Desse modo, Nicole Picard apresenta duas abordagens diferentes para as operações aritméticas: as operações entre conjuntos (união, diferença, separação) e a noção de funções. A Figura 5 ilustra a representação dos dois pontos de vista para a operação 3 x 4 $=12$.

Figura 5 - Representação da operação 3 x $4=12$ dos pontos de vista conjuntista $\mathrm{e}$ funcional

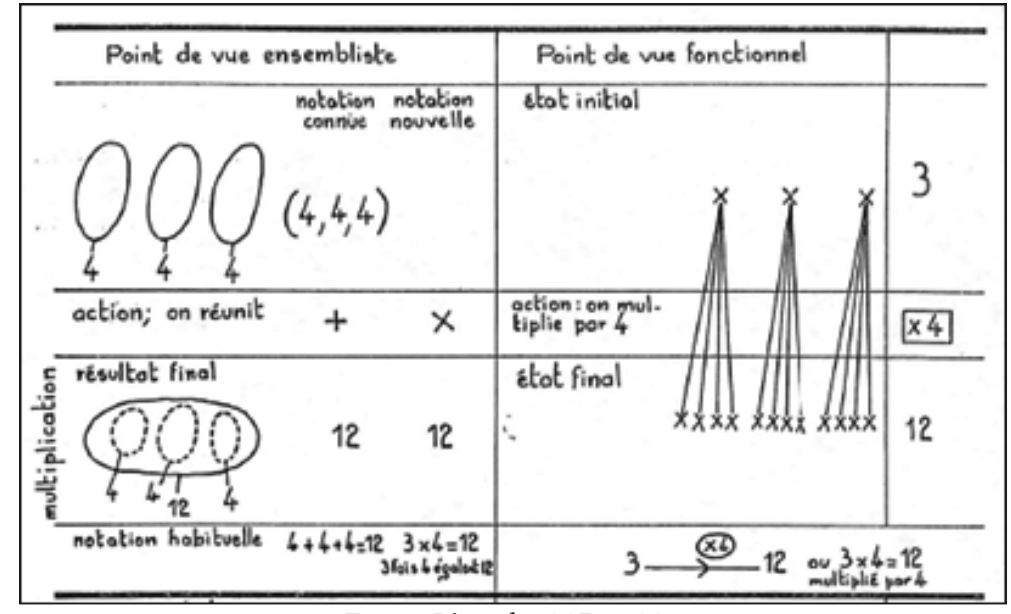

Fonte: Picard (1967, p. 26).

Acreditamos que essa metodologia proposta pela autora foi motivo de curiosidade e estudo das professoras do Instituto de Educação, estimulando a tradução de partes de suas obras.

A introdução dos conceitos de operação ou função utilizando máquinas aparece em materiais e atividades propostos em cursos de formação envolvendo conteúdos do movimento da matemática moderna. O material Algumas sugestões para introduzir o conceito de ope- 
ração ${ }^{7}$, usado no Curso de Atualização sobre o Ensino de Matemática em algum momento dos anos 1970 ou 1980, reproduz uma sequência de abordagem em que as máquinas são o tema central da proposta. Em conversa informal, no primeiro momento, a professora deveria indagar se os estudantes conheciam o termo operação. Após as manifestações dos alunos e poucas intervenções da professora, teria início a conversa sobre as máquinas, utilizando a experiência de vida dos alunos como fio condutor da conversa. Trazendo a mesma ideia de Nicole Picard, de que o conceito de máquinas é familiar às crianças, o texto propõe uma introdução aos conceitos de operação e função.

Em material do Curso de Didática da Matemática, elaborado por Nelcy Borella, em algum momento das décadas de 1970 ou 1980, os livros A la conquête du nombre II e Journal de mathématique I constam como bibliografia da atividade. A Figura 6 apresenta um recorte do material Sugestões de atividades sobre estados e operadores, em que vemos clara referência às máquinas e aos blocos lógicos, material didático também utilizado nos estudos e atividades do Laboratório de Matemática.

\section{Figura 6 - Recorte de atividade Sugestões de atividades sobre estados e operadores}

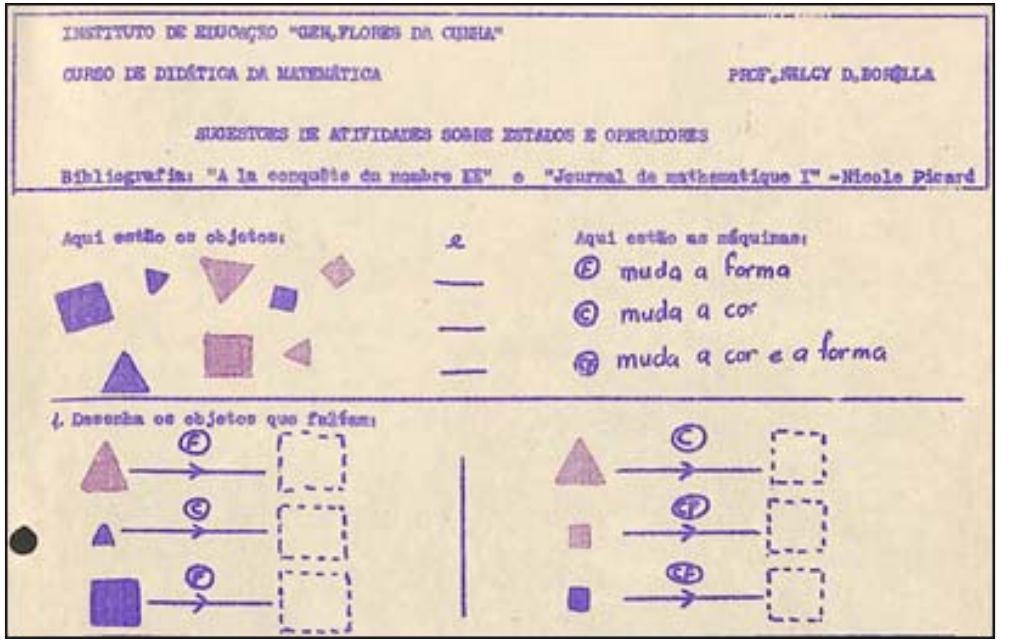

Fonte: Disponível em http://hdl.handle.net/20.500.11959/10000001146.

Vestígios das ideias de Nicole Picard aparecem em vários outros documentos esparsos, como as Sugestões de Esther Pillar Grossi à Experiência de Introdução da Matemática Moderna no $1^{\circ}$ ano Primário no Grupo Escolar Monteiro Lobato sob a orientação da professora Yeda Simões Pires (tombo 846) ${ }^{8}$, ou um material de planejamento do Curso de Atualização sobre o Ensino de Matemática-Jardim de Infância ${ }^{9}$, de 1978, ou as Sugestões de fichas gráficas, usadas no Curso de Atualização sobre Ensino de Matemática $1^{\mathrm{a}}$ a $4^{\mathrm{a}}$ série, de $1983^{10}$ (tombo 1746). 
Máquinas e Números

Vemos, portanto, que as ideias de Nicole Picard foram referidas em materiais produzidos e usados em cursos para professores, ao longo dos anos 1970 e 1980. E assim, circularam para além do Instituto de Educação, pelas mãos de professoras que frequentavam os cursos de atualização ou buscavam orientação junto ao Laboratório de Matemática. Foram experimentadas no Colégio de Aplicação da Universidade Federal do Rio Grande do Sul (UFRGS), em 1973, quando o ensino de Matemática era orientado pelas professoras Gelsa Knijnik e Léa Fagundes, que também participavam do Laboratório de Matemática do Instituto.

\section{Máquinas nos planejamentos curriculares do novo ensino de primeiro grau}

Marcas das ideias de Nicole Picard também foram encontradas em documentos que propõem uma orientação curricular para o ensino de primeiro grau, constituído a partir da fusão do primário e do ginásio pela Lei n. 5692/71.

Nas diretrizes curriculares propostas pela Secretaria Estadual de Educação do Rio Grande do Sul (1972), as ideias do movimento da matemática moderna estão presentes. Mas a ideia de enfocar funções nos primeiros anos do ensino de primeiro grau não foi adotada. Não há indícios dos conceitos abordados por Nicole Picard no texto oficial. Mas eles estão presentes em outros textos elaborados no mesmo período.

O documento Linhas metodológicas para o ensino-aprendizagem dos conteúdos matemáticos no $1^{\circ}$ grau, elaborado em 1974, traz uma proposta metodológica a ser instituída no primeiro grau. Na reformulação do ensino-aprendizagem de matemática, com referência nos trabalhos de Dienes e Picard, são elencados cinco princípios orientadores das metodologias a serem trabalhadas em sala de aula: princípio da construtividade, princípio da variabilidade matemática, princípio da variabilidade perceptual, princípio do constraste e princípio da utilização de representações (Instituto..., 1974).

Já o documento Seleção de conteúdos de matemática - Ensino de Primeiro Grau, de 1976, apresenta uma "tentativa de estabelecer uma linha sequencial de conteúdos matemáticos para o Instituto de Educação General Flores da Cunha”, para o ensino de primeiro grau. Para a segunda série, são indicados os temas Função - máquina - operador como preparação para o estudo dos sistemas de numeração e dos "fatos básicos da adição e da subtração". Na terceira série, a máquina de inchar e a máquina de murchar deveriam preceder o estudo da multiplicação e da divisão (Instituto..., 1976).

Em 1972, o GEEMPA, presidido por Esther Pillar Grossi, iniciou, sob a orientação de Dienes, uma experimentação com oito classes-piloto, que deveria ter a duração dos oito anos correspondentes ao primeiro grau. A proposta curricular para a primeira série é inspirada na experimentação desenvolvida pelo IPN, na França: "A organização desta sequência de conteúdos foi feita paralelamente com experimentação 
em escolas, por professores do GEEMPA, e se inspirou para as primeiras séries nas pesquisas de Nicole Picard em Paris" (GEEMPA, 1975, p. 26). A ideia das máquinas está presente na programação para a primeira série, como componente da construção do conceito de número cardinal; mas aparece também na programação para a segunda e a terceira série; enquanto os conceitos de operador e de função são mencionados em todas as séries.

Vemos que as propostas de Nicole Picard deixaram marcas em diferentes propostas curriculares elaboradas em meados dos anos 1970, em Porto Alegre, indicando que suas ideias foram estudadas, difundidas e colocadas em prática em salas de aula do ensino primário, no Instituto de Educação e em outras escolas.

É interessante registrar que a maior parte das traduções de textos de Nicole Picard encontradas no acervo são dos anos de 1975 e 1976, na mesma época em que foram elaboradas essas propostas curriculares. As traduções eram atribuição da professora Maria Feijó Monteiro e revisadas pela professora Ely Machado Campos, então coordenadora do Laboratório de Matemática. A professora Ely Campos foi, portanto, uma das principais impulsionadoras da divulgação das ideias de Nicole Picard em Porto Alegre.

\section{Marcas de um diálogo entre professoras modernas}

As dinâmicas de mudança do ensino de matemática foram diferentes, na França e no Brasil. Na França, as discussões sobre um novo programa de matemática para o ensino primário tiveram início em 1969. Segundo d'Enfert (2011), havia duas propostas em debate na CEEM: uma, proposta pela equipe do IPN, que pretendia uma revisão ampla, a ser aplicado paulatinamente, série a série; outra, defendida pelos inspetores-gerais do ensino, mais moderada. A segunda alternativa foi a adotada; em 2 de janeiro de 1970, um decreto ministerial introduz mudanças no programa do ensino primário, que vigorava desde 1945. $\mathrm{Na}$ Circular que acompanha o decreto, aparece a ideia de operador, a ser estudada no quarto e quinto ano primário, mas não com o sentido que tinha na experimentação do IPN - como preparação para a construção da ideia de número e de operações numéricas.

Sobre esse programa, Nicole Picard (1973, p. 9) comenta:

Como se poderia esperar, foi o segundo ponto de vista o adotado pela Comissão: alguns de seus membros eram pouco favoráveis à liberdade pedagógica e outros, embora considerassem que o primeiro projeto era melhor, consideravam-no prematuro e inaceitável para a administração. Uma tal autocensura é, na minha opinião, uma má estratégia para avançar.

[...] Na verdade, apesar de tudo, as pesquisas efetuadas tiveram uma influência certa sobre a redação do programa e dos comentários. Uma boa parte dos redatores de fato pensou esse programa em função das possibilidades de 
abstração das crianças. A introdução (na verdade não explicitada) da função linear no quarto e quinto ano é fruto de uma experimentação séria. [...] Mas justamente, sempre com o objetivo de não traumatizar os professores, de redação em redação, os comentários oficiais cada vez menos explicitaram as novas introduções. Os comentários apresentam exemplos - o que é novo e é bom - mas o porquê das mudanças não é precisado. Tampouco se esclarece que a experiência mostra que uma abstração só pode ser feita substituindo métodos dogmáticos, aprendizagens de regras e de vocabulário, por métodos que mobilizam a atividade e a participação das crianças.

As discussões coordenadas pelo IPN foram suspensas também em 1970. Pesquisas e debates sobre a mudança no ensino de matemática passaram a ser encampados pelos Institut de recherche sur l'enseignement des mathématiques (IREMs), criados a partir de demandas dos professores de matemática do ensino secundário. A CEEM, encarregada de planejar a continuidade da reforma, encerrou seus trabalhos em 1973. Ao final da década, foram publicados novos programas, que procuravam conciliar as mudanças de 1970 com a tônica nas habilidades de cálculo, incluindo a memorização das tabuadas de adição e multiplicação (D'Enfert, 2017). Assim, podemos considerar que na França houve um arrefecimento importante do movimento modernizador, embora os livros de Nicole Picard e muitas outras propostas continuassem circulando.

No Brasil, os debates sobre a modernização do ensino seguiram ritmos e tendências diferentes em cada região. Em Porto Alegre, as iniciativas das professoras do Instituto de Educação e do GEEMPA promoveram um amplo debate sobre as propostas de renovação do ensino primário, sustentadas pela perspectiva construtivista. Zoltan Dienes, em colaboração com o GEEMPA, veio várias vezes a Porto Alegre para ministrar cursos, palestras e acompanhar a experimentação em curso. Seus livros foram publicados em português e seu nome circulou na mídia, bem mais amplamente que o nome de Nicole Picard.

Os vestígios encontrados no Laboratório de Matemática, contudo, nos mostram que os textos de Nicole Picard também foram referências relevantes para os esforços de renovação do ensino desenvolvidos no Instituto de Educação, que envolveram desde a formação continuada de professores até a elaboração de novos currículos. E essa referência não se limitou ao tempo em que Nicole Picard dirigia a preparação de uma reforma na França, mas perdurou até os anos 1980, quando muitos autores e professores consideravam que a matemática moderna era um assunto do passado.

Podemos pensar que o importante papel desempenhado por Picard no IPN e na CEEM contribuiu para que as professoras do Instituto de Educação dessem atenção aos seus escritos. Mas, para entender o modo como se mobilizaram para estudar, traduzir e divulgar seus textos é necessário considerar como as propostas de Picard dialogavam com os esforços de renovação empreendidos no Instituto. 
Nicole Picard alinhava-se com o construtivismo preconizado por Dienes e sustentado pelas pesquisas de Piaget. Coerente com a perspectiva construtivista, suas propostas didáticas eram debatidas em reuniões amplas, discutidas com as professoras e avaliadas e corrigidas a partir da experimentação em sala de aula, minuciosamente relatada em seus artigos. A condução do experimento, testemunhada e vivenciada por Esther Grossi, durante seu estágio no IPN, é um exemplo interessante de diálogo entre professores licenciados em Matemática e professores e formadores do âmbito do ensino primário, como se buscou fazer também no Instituto de Educação.

Os livros de Nicole Picard eram voltados para o uso em sala de aula, contendo atividades que podiam ser imediatamente replicadas e orientações detalhadas aos professores sobre sua condução. Muitas fichas dirigidas aos alunos sequer demandavam tradução, pois continham apenas figuras. Esse formato - construído para dialogar com professores e alunos do ensino primário na França - certamente favoreceu também o diálogo das professoras do Instituto com seus textos.

\section{Considerações finais}

No início deste texto, falamos de um encontro entre uma autora e suas tradutoras. Esther Pillar Grossi conviveu e aprendeu com Nicole Picard, durante seu estágio no IPN, em Paris. Esse convívio marcou sua trajetória de educadora e pesquisadora, sendo por ela rememorado muitos anos depois. Mas o encontro a que nos referimos se deu, sobretudo, pelos textos que circularam no Instituto de Educação, em sua versão original ou traduzida. Foi por meio desses textos que muitas outras professoras frequentadoras do Laboratório conheceram Nicole Picard, e souberam de suas propostas e das experimentações que conduzia.

Ao tratarmos do encontro entre Nicole Picard e as professoras do Instituto de Educação, percebemos uma conexão que foi fruto da iniciativa de educadoras. A mobilização das professoras do Instituto é testemunhada pelas traduções e pelos relatórios. Mas podemos pensar que o encontro também resultou do esforço de Nicole Picard para dialogar com professores e atores da escola primária, sugerindo uma sequência e um repertório de atividades, incentivando sua autonomia e iniciativa, recomendando a flexibilização dos programas e dos procedimentos de avaliação.

Para essa conexão não houve incentivo, muito menos imposição de governos. Como outros trabalhos já mostraram, não é possível compreender a matemática moderna sem considerar o engajamento de professores que tinham o desejo de inovar. Por outro lado, podemos pensar que a enorme mobilização internacional em torno da modernização do ensino favoreceu a divulgação de textos como os de Nicole Picard e a própria ideia de que era possível uns aprenderem com as experimentações de outros, como a própria Picard buscou aprender com os projetos norte-americanos e ingleses, e com autores franceses que se interessavam pelo ensino primário. 
Nicole Picard propunha todo um reordenamento das aprendizagens na escola primária. As traduções encontradas no Laboratório de Matemática tratam de alguns dos temas abordados em seus textos e artigos. Destacamos, neste texto, o estudo das operações numéricas articulado à ideia de função, desde as séries iniciais, uma abordagem que ainda parece hoje ousada. Como essas ideias foram experimentadas e avaliadas em salas de aula da escola primária em Porto Alegre? Esse é um tema para investigações futuras.

Talvez os efeitos mais importantes e duradouros das leituras de autores da matemática moderna possam ser percebidas na constituição do ensino de matemática como campo de pesquisa, em Porto Alegre. Os escritos de Nicole Picard foram importantes, sobretudo, para apontar a possibilidade e a fecundidade da sala de aula como espaço e foco de investigação. O campo de pesquisa avançou, nas décadas seguintes: Léa Fagundes, Gelsa Knijnik e Nelcy Borella são algumas das figuras que participaram da vida do Laboratório nos anos 1970 e se constituíram em figuras de referência, no país e no âmbito internacional, no campo da educação matemática ou da psicologia cognitiva.

O olhar ao passado pode nos ajudar a pensar o presente? Pensamos que sim, de diferentes modos. Uma das reflexões suscitada pelo achado dos documentos diz respeito a como professores podem ser protagonistas de sua própria formação quando têm a possibilidade de dialogar e pensar sobre os programas, ao invés de serem vigiados para executá-los. E à variedade de ressonâncias que essa mobilização pode provocar.

Recebido em 15 de março de 2021 Aprovado em 19 de maio de 2021

\section{Notas}

1 Mediante Termo de Guarda assinado pela direção do Instituto de Educação e pelas pesquisadoras responsáveis.

2 A constituição do acervo do Laboratório de Matemática do IE foi uma das principais atividades e metas do projeto "Estudar para ensinar: práticas e saberes matemáticos das Escolas Normais do Rio Grande do Sul”, financiado pela Chamada Universal 2016 do CNPq (Búrigo et al., 2016).

3 Esses itens foram digitalizados e compõem a subcoleção Documentos do Laboratório de Matemática do Instituto de Educação General Flores da Cunha (1961-1979) da coleção digital Práticas e saberes matemáticos nas escolas normais do Rio Grande do Sul, hospedada no site do Centro de Documentação e Acervo Digital da Pesquisa (CEDAP) da Universidade Federal do Rio Grande do Sul.

4 Para os textos reprografados, foram encontrados vários exemplares; o número do item que consta no Quadro é o do exemplar que consta na coleção digital acima mencionada. Em alguns casos, foram digitalizados dois ou mais exemplares, por conterem anotações e outras marcas consideradas relevantes.

5 Adotamos aqui a classificação adotada pela Bibliothèque Nationale de France, observando que o formato não é o usual de um livro encadernado. 
6 No Brasil esse material foi divulgado e conhecido como blocos lógicos de Dienes. Picard refere-se ao material como blocos de Hull-Dienes. O próprio Dienes (1967) considera que o material foi criado por Vigotsky e adaptado por William Hull.

7 Disponível em:<http://hdl.handle.net/20.500.11959/10000001721>. Acesso em: 12 mar. 2021.

8 Item 846 do acervo do Laboratório de Matemática do Instituto de Educação, não digitalizado.

9 Disponível em:<http://hdl.handle.net/20.500.11959/10000001085>. Acesso em: 12 mar. 2021.

10 Disponível em: <http://hdl.handle.net/20.500.11959/10000001746>. Acesso em: 12 mar. 2021

\section{Referências}

BERTRAND, Romain. Rencontres impériales. L'histoire connectée et les relations euro-asiatiques. Revue d'histoire moderne \& contemporaine, Paris, Société d'Histoire Moderne \& Contemporaine, v. 54, n. 4, p. 69-89, 2007.

BONFADA, Elisete Maria. A matemática na formação das professoras normalistas: o Instituto de Educação General Flores da Cunha em tempos de matemática moderna. 2018. 206 f. Dissertação (Mestrado em Ensino de Matemática) - Programa de Pós-Graduação em Ensino de Matemática, Universidade Federal do Rio Grande do Sul, Porto Alegre, 2018.

BÚRIGO, Elisabete Zardo. Movimento da matemática moderna no Brasil: estudo da ação e do pensamento de educadores matemáticos nos anos 60. 1989. 293 f. Dissertação (Mestrado em Educação) - Programa de Pós-Graduação em Educação, Universidade Federal do Rio Grande do Sul, Porto Alegre, 1989.

BÚRIGO, Elisabete Zardo. Joana Bender, educadora matemática. In: GUTIERREZ, Ana Lérida Pacheco; BÚRIGO, Elisabete Zardo (Org.). Personagens do Instituto de Matemática e Estatística. Porto Alegre: no prelo.

BÚRIGO, Elisabete Zardo; DALCIN, Andreia; DYNNIKOV, Circe Mary Silva da Silva; FISCHER, Maria Cecília Bueno; RIOS, Diogo Franco. Estudar para ensinar: práticas e saberes matemáticos nas escolas normais do Rio Grande do Sul (1889-1970). Projeto de pesquisa submetido à Chamada Universal 2016 do CNPq. Não publicado.

DALCIN, Andreia. Entre documentos, memórias e pó: processo de revitalização de um laboratório de matemática. In: COSTELLA, Roselane Zordan; HOFSTAETTER, Andrea; STURM, Ingrid Nancy; UBERTI, Luciane (Org.). Percursos da prática de sala de aula. São Leopoldo: Oikos, 2016. P. 44-55.

DALCIN, Andreia; BONFADA, Elisete Maria; RHEINHEIMER, Juliana Merceds. Odila Barros Xavier e o ensino de matemática: percursos de uma professora formadora. Educação Matemática em Revista-RS, Brasília, Sociedade Brasileira de Educação Matemática, v. 2, n. 19, p. 9-20, 2018.

D’AMBROSIO, Beatriz Silva. Dinâmica e as consequências do movimento da matemática moderna na educação matemática no Brasil. Campinas: Mercado de Letras, 2017.

D'ENFERT, Renaud. Une réforme ambigüe: l'introduction des 'mathématiques modernes' à l'école élémentaire (1960-1970). In: D'ENFERT, Renaud; KAHN, 
Pierre (Ed.). Le temps des réformes. Disciplines scolaires et politiques éducatives sous la Cinquième République: les années 1960. Grenoble: Presses Universitaires de Grenoble, 2011. P. 53-73.

D'ENFERT, Renaud. Quelles mathématiques pour l'école élémentaire? Une perspective historique (1945-début XXIe siècle). Education \& Formations, Paris, Ministère de l'Éducation nationale, n. 94, p. 7-22, 2017.

GAL, Roger. Présentation. Le courrier de la recherche pédagogique, Paris, Institut National Pédagogique, n. 27, p. 3, 1966.

GEEMPA. Grupo de Estudos em Ensino de Matemática de Porto Alegre. Reformulação Metodológica do Ensino da Matemática no $1^{\circ}$ Grau. Porto Alegre: 1975. Disponível em: <https://repositorio.ufsc.br/handle/123456789/201230>. Acesso em: 12 mar. 2021.

GROSSI, Esther Pillar. Entrevista concedida a Elisabete Zardo Búrigo. Porto Alegre: 1988. Não publicada.

GROSSI, Esther Pillar. Entrevista concedida a Elisabete Zardo Búrigo, Luiz Henrique F. Pereira, Maria Cecilia Bueno Fischer, Monica Bertoni Santos. Porto Alegre: setembro de 2007a. Não publicada.

GROSSI, Esther Pillar. La contribution des idées de Gérard Vergnaud à la démocratisation des apprentissages au Brésil. In: MERRI, Maryvonne (Ed.). Activité humaine et conceptualisation. Toulouse: Presses universitaires du Midi, 2007b. P. 307-319.

INSTITUTO de Educação General Flores da Cunha. Laboratório de Matemática. Relatório de atividades de 1961. Porto Alegre: 1961. Disponível em: <http://hdl. handle.net/20.500.11959/10000001564>. Acesso em: 12 mar. 2021.

INSTITUTO de Educação General Flores da Cunha. Laboratório de Matemática. Relatório das atividades realizadas no decorrer do $1^{\circ}$ semestre 1965 . Porto Alegre: 1965. Disponível em: <http://hdl.handle.net/20.500.11959/10000001565>. Acesso em: 12 mar. 2021.

INSTITUTO de Educação General Flores da Cunha. Curso de Didática da Matemática Moderna para Escolas Primárias. Relatório do $1^{\mathbf{0}}$ ano de atividades do curso. Porto Alegre: 1967a. Disponível em: <http://hdl.handle. net/20.500.11959/10000001316>. Acesso em: 12 mar. 2021.

INSTITUTO de Educação General Flores da Cunha. Laboratório de Matemática. Relatório de 1967. Porto Alegre: 1967b. Disponível em: <http://hdl.handle. net/20.500.11959/10000001667>. Acesso em: 12 mar. 2021.

INSTITUTO de Educação General Flores da Cunha. Laboratório de Matemática. Relatório de 1970. Porto Alegre: 1970. Disponível em: <http://hdl.handle. net/20.500.11959/10000001666>. Acesso em: 12 mar. 2021.

INSTITUTO de Educação General Flores da Cunha. Laboratório de Matemática. Relatório de 1971. Porto Alegre: 1971. Disponível em: <http://hdl.handle. net/20.500.11959/10000001672>. Acesso em: 12 mar. 2021.

INSTITUTO de Educação General Flores da Cunha. Linhas Metodológicas para o Ensino-Aprendizagem dos Conteúdos Matemáticos no $1^{\circ}$ grau. Porto Alegre: 1974. 13 f. Disponível em: <http://hdl.handle.net/20.500.11959/10000001701>. Acesso em: 12 mar. 2021.

INSTITUTO de Educação General Flores da Cunha. Seleção de conteúdos de matemática - Ensino de Primeiro Grau. Porto Alegre: 1976. 89 f. Disponível em: <http://hdl.handle.net/20.500.11959/10000001702>. Acesso em: 12 mar. 2021. 
LEGRAND, Louis. Présentation. Les mathématiques en marche. Le courrier de la recherche pédagogique, Paris, Institut National Pédagogique, n. 31, p. 3-4, 1967.

OLIVEIRA, Maria Cristina Araújo de; LEME DA SILVA, Maria Célia; VALENTE, Wagner Rodrigues. O movimento da matemática moderna: história de uma revolução curricular. Juiz de Fora: UFJF, 2011.

PIAGET, Jean. Les structures mathématiques et les structures opératoires de l'intelligence. In: Piaget, Jean; Beth, Evert Willem; Dieudonné, Jean; Lichnerowicz, André; Choquet, Gustave; Gattegno, Caleb. L'enseignement des mathématiques. Neuchâtel: Delachaux \& Niestlé, 1955. p. 11-34.

PICARD, Nicole. Une expérience d'enseignement de la mathématique au cours élémentaire. Le courrier de la recherche pédagogique, Paris, Institut National Pédagogique, n. 27, p. 12-76, 1966.

PICARD, Nicole. Recherches sur l'initiation aux mathématiques au cycle élémentaire. Le courrier de la recherche pédagogique, Paris, Institut National Pédagogique, n. 31, p. 5-41, 1967.

PICARD, Nicole. Journal de Mathématique I. C. E. 2. Commentaires pour le maître. Paris: OCDL, 1971.

PICARD, Nicole. Recherche dans le premier degré. Cahiers pédagogiques, Biarritz, Cercle de Recherche et d'Action Pédagogiques, n. 110, p. 8-12, 1973.

RIO GRANDE DO SUL. Ensino de $1^{\circ}$ Grau no Rio Grande do Sul: currículos das $1^{\mathrm{a}}, 2^{\mathrm{a}}$ e $3^{\mathrm{a}}$ séries. Porto Alegre: 1972 .

SILVA, Sara Regina da. A formação de professores no Instituto de Educação General Flores da Cunha: o curso de didática da matemática moderna na escola primária (1966 - 1972). 2019. 164 f. Dissertação (Mestrado em Ensino de Matemática) - Programa de Pós-Graduação em Ensino de Matemática, Universidade Federal do Rio Grande do Sul, Porto Alegre, 2019.

XAVIER, Odila Barros. Um problema em marcha. Porto Alegre: 1963. Disponível em: <http://hdl.handle.net/20.500.11959/10000001852>. Acesso em: 12 mar. 2021.

Elisabete Zardo Búrigo é Doutora em Educação pela Universidade de São Paulo. Professora titular e docente do Programa de Pós-Graduação em Ensino de Matemática da Universidade Federal do Rio Grande do Sul.

ORCID: https://orcid.org/0000-0003-1532-7586

E-mail: 00009949@ufrgs.br

Nícolas Giovani da Rosa é licenciado em Matemática e mestrando do Programa de Pós-Graduação em Ensino de Matemática da Universidade Federal do Rio Grande do Sul. É professor da rede estadual de ensino do Rio Grande do Sul.

ORCID: https://orcid.org/0000-0002-2794-5747

E-mail: nicolasgiovani20@gmail.com

Editor-responsável: Luís Armando Gandin

Este é um artigo de acesso aberto distribuído sob os termos de uma Licença Creative Commons Atribuição 4.0 Internacional. Disponível em: <http:// creativecommons.org/licenses/by/4.0>. 